\title{
Interplay between neural-cadherin and vascular endothelial-cadherin in breast cancer progression
}

\author{
Maryam Rezaei ${ }^{1,4}$, Katrin Friedrich ${ }^{1}$, Ben Wielockx ${ }^{2}$, Aleksandar Kuzmanov ${ }^{1,5}$, Antje Kettelhake ${ }^{1}$, Myriam Labelle ${ }^{3}$, \\ Hans Schnittler ${ }^{4}$, Gustavo Baretton ${ }^{1}$ and Georg Breier ${ }^{1 *}$
}

\begin{abstract}
Introduction: Deregulation of cadherin expression, in particular the loss of epithelial (E)-cadherin and gain of neural (N)-cadherin, has been implicated in carcinoma progression. We previously showed that endothelial cellspecific vascular endothelial (VE)-cadherin can be expressed aberrantly on tumor cells both in human breast cancer and in experimental mouse mammary carcinoma. Functional analyses revealed that VE-cadherin promotes tumor cell proliferation and invasion by stimulating transforming growth factor (TGF)- $\beta$ signaling. Here, we investigate the functional interplay between $\mathrm{N}$-cadherin and VE-cadherin in breast cancer.
\end{abstract}

Methods: The expression of $\mathrm{N}$-cadherin and VE-cadherin was evaluated by immunohistochemistry in a tissue microarray with 84 invasive human breast carcinomas. VE-cadherin and $\mathrm{N}$-cadherin expression in mouse mammary carcinoma cells was manipulated by RNA interference or overexpression, and cells were then analyzed by immunofluorescence, reverse transcriptase-polymerase chain reaction, and western blot. Experimental tumors were generated by transplantation of the modified mouse mammary carcinoma cells into immunocompetent mice. Tumor growth was monitored, and tumor tissue was subjected to histological analysis.

Results: VE-cadherin and N-cadherin were largely co-expressed in invasive human breast cancers. Silencing of Ncadherin in mouse mammary carcinoma cells led to decreased VE-cadherin expression and induced changes indicative of mesenchymal-epithelial transition, as indicated by re-induction of E-cadherin, localization of $\beta$-catenin at the cell membrane, decreased expression of vimentin and SIP1, and gain of epithelial morphology. Suppression of N-cadherin expression also inhibited tumor growth in vivo, even when VE-cadherin expression was forced.

Conclusions: Our results highlight the critical role of $\mathrm{N}$-cadherin in breast cancer progression and show that $\mathrm{N}$-cadherin is involved in maintaining the malignant tumor cell phenotype. The presence of $\mathrm{N}$-cadherin prevents the re-expression of E-cadherin and localization of $\beta$-catenin at the plasma membrane of mesenchymal mammary carcinoma cells. $\mathrm{N}$-cadherin is also required to maintain the expression of $\mathrm{VE}$-cadherin in malignant tumor cells but not vice versa. Thus, $\mathrm{N}$-cadherin acts in concert with VE-cadherin to promote tumor growth.

\section{Introduction}

Cadherins are a family of transmembrane proteins that, together with their associated intracellular catenins, have important functions in cell-cell adhesion. Different cell types express different members of the cadherin family. Epithelial (E)-cadherin is a key component of adherens junctions in epithelial cells and functions as a suppressor of tumor growth and invasion. Perturbation of its function leads to an invasive phenotype in many

\footnotetext{
* Correspondence: georg.breier@uniklinikum-dresden.de

'Department of Pathology, University of Dresden, Fetscherstrasse 74,

D-01307 Dresden, Germany

Full list of author information is available at the end of the article
}

tumors [1-3]. Neural (N)-cadherin is expressed in neural tissues and fibroblasts, where it mediates a less stable and more dynamic form of cell-cell adhesion [1-4]. Vascular endothelial (VE)-cadherin is the primary component of endothelial cell adherens junctions and has an important function in regulating vascular permeability and angiogenesis [5]. Because of the important role played by cadherins in cell recognition, adhesion, and signaling, modulation of their function and expression has significant implications for the progression of tumors [1,6-10]. For instance, a switch from E-cadherin to $\mathrm{N}$-cadherin expression contributes to increased tumor cell migration, invasion and metastasis [8-10].
C Biomed Central 
Aberrant expression of VE-cadherin was first detected in aggressive melanoma cells and in some cases of sarcoma [11-13]. A recent study from our group has revealed that VE-cadherin is expressed aberrantly in a subset of tumor cells in human breast cancer [7]. In a mouse mammary carcinoma model, VE-cadherin expression was induced in cancer cells that had undergone epithelial-mesenchymal transition (EMT). Functional experiments showed that VE-cadherin promotes malignant tumor cell proliferation and invasion by enhancing the protumorigenic transforming growth factor-beta (TGF$\beta$ ) pathway. However, the functional interaction between VE-cadherin and $\mathrm{N}$-cadherin during tumor progression is poorly characterized to date.

EMT was first described by Elizabeth Hay in the 1980s as a central process in early embryonic morphogenesis [14]. The initial step of EMT includes the loss of epithelial markers such as E-cadherin via its transcriptional repression and the gain of mesenchymal markers such as vimentin. As a consequence, the cadherin-binding partner $\beta$-catenin can dissociate from the E-cadherin complex at the plasma membrane and translocate to the nucleus where it participates in EMT signaling and activates genes involved in tumor progression [15]. Epithelial cells then lose their typical baso-apical polarization as cell-cell junctions disassemble. Additionally, the cytoskeleton undergoes dynamic cortical actin remodeling and gains the front-rear polarization that facilitates cell movement [16]. Finally, cell-matrix adhesion changes as proteolytic enzymes such as matrix metalloproteases are activated $[17,18]$. The transition from an epithelial to mesenchymal phenotype is reversible; for example, several rounds of EMT and mesenchymalepithelial transition (MET) occur during development as cells differentiate and the complex three dimensional structure of internal organs forms [19]. There is increasing evidence that EMT also facilitates the dissemination of tumor cells to form distant metastasis [20]. Various publications have described a switch between the epithelial and mesenchymal phenotypes through EMT and MET in models of colorectal [21], bladder [22], ovarian [23] and breast cancer [24]. These findings indicate that the phenotypic conversion of tumor cells in the metastatic cascade is multifaceted, with EMT being critical for the initial transformation from benign to invasive carcinoma and the spreading of tumor cells, but MET occurring at the site of metastatic colonization [6].

The mouse mammary carcinoma model that we have previously used to study the expression of cadherins [7] utilizes tumor cell lines that represent different stages of tumor progression: Ep5 cells are tumorigenic mammary epithelial cells transformed by the v-Ha-Ras oncogene, whereas Ep5ExTu cells, isolated from Ep5 cell tumors grown in mice, have undergone EMT in vivo and present a mesenchymal, invasive and angiogenic phenotype $[25,26]$. We observed that VE-cadherin expression is induced in these murine breast cancer cells during (TGF- $\beta$-mediated) EMT [7]. On the other hand, E-cadherin expression was downregulated, and $\mathrm{N}$-cadherin levels remained unchanged. Silencing VE-cadherin expression inhibited tumor cell proliferation and invasion in vitro, and experimental tumor growth in mice. However, the role of $\mathrm{N}$-cadherin and its potential interaction with VE-cadherin in this model is unclear. Here, we investigate the influence of $\mathrm{N}$-cadherin on EMT and tumor progression in Ep5ExTu cells. Silencing N-cadherin significantly decreased VE-cadherin expression and stimulated Ep5ExTu cells to re-express E-cadherin at the cell surface. This promoted localization of $\beta$-catenin at the plasma membrane and induced the cells to undergo MET. Efficient silencing of N-cadherin expression in Ep5ExTu cells consistently inhibited tumor growth, and complete tumor regression was even seen in some cases. Taken together, these results reveal a novel interplay between classical cadherins in breast cancer progression.

\section{Materials and methods \\ Cell culture}

Ep5 and Ep5ExTu cells were cultured as described [26] in Dulbecco's modified Eagle's medium (DMEM-F12; Lonza, Basel, Switzerland) supplemented with $15 \%$ fetal calf serum (FCS). 293T cells were kept in DMEM Glutamax (Gibco, Darmstadt, Germany) supplemented with $10 \%$ FCS.

\section{Generation of VE-cadherin or N-cadherin-silenced Ep5ExTu cells}

Oligonucleotides (Eurogentec, Seraing, Belgium) encoding small interfering RNA (siRNA) molecules specific for mouse VE-cadherin (5'-GUCUCUGAGU ACUUCCU UA-3') or N-cadherin (5'-GGAUGUGCAG GAAGGACA G-3' and 5'-UGUCAAUGGG GUUCUCCAC-3') were designed and verified to be specific for each cadherin by a Blast search (National Center for Biotechnology Information, Bethesda, MD, USA) against the mouse genome. A scrambled oligonucleotide sequence without significant homology to murine sequences (5'-AGUCGCUUAG AAACGAGAA-3') was used as a control. These oligonucleotides were then cloned into the lentiviral vector, pLVTHM, according to the guidelines provided by Tronolab (Laboratory of Virology and Genetics, École Polytechnique Fédérale de Lausanne, Switzerland). Viral particles were produced by transient co-transfection of $293 \mathrm{~T}$ cells with the recombinant pLVTHM lentivector constructs, the packaging vector psPAX2 and the envelope vector pMD2.G. Ep5ExTu cells were then transduced with the lentiviral particles contained in supernatants of transfected $293 \mathrm{~T}$ cells, and stable cell lines were selected 
by fluorescence-activated cell sorting (FACS) on the basis of green fluorescent protein (GFP) expression. Clones of Ep5ExTu cells expressing Sh-VE-cadherin and Sh-Ncadherin were expanded and the expression of VE-cadherin and N-cadherin was monitored by immunoblot. Experiments were approved by the Sächsisches Staatsministerium für Umwelt und Landwirtschaft, Dresden, Germany (Re: 55-8811.72/69).

\section{Silencing VE-cadherin or N-cadherin in human breast cancer cell lines}

Human SUM 149 cells were cultured in DMEM-F12 supplemented with $15 \%$ FCS. Silencing of human N-cadherin or human VE-cadherin was performed by using SMARTpools (Dharmacon, Lafayette, CO, USA). Cells $\left(1-2 \times 10^{5}\right)$ were seeded in $2 \mathrm{ml} \mathrm{DMEM}, 15 \%$ FCS in 6-well plates $24 \mathrm{~h}$ before transfection. The medium was replaced by $2 \mathrm{ml}$ Opti-MEM I (Invitrogen, Karlsruhe, Germany) $1 \mathrm{~h}$ before transfection. 100 pmol siRNA was mixed with 500 $\mu \mathrm{l}$ Lipofectamine 2000 (Invitrogen) diluted in a final volume of $1 \mathrm{ml}$ Opti-MEM I and incubated for $30 \mathrm{~min}$ at room temperature to allow the formation of complexes. For transfection, the medium was removed and the DNALipofectamine mixture was added to the cells, which were then incubated at $37^{\circ} \mathrm{C} .1 \mathrm{ml}$ DMEM, $15 \%$ FCS was added $6 \mathrm{~h}$ after transfection and the cells were cultivated for another $24 \mathrm{~h}$ before analysis.

\section{Generation of Sh-N-cadherin cell lines stably expressing VE-cadherin}

Mouse cDNA encoding VE-cadherin (kindly provided by Prof. D. Vestweber, Münster, Germany) was cloned into the P6NST50 vector (kindly provided by Prof. D. Lindemann, Dresden, Germany). Ep5ExTu (Sh-N-cad2) cells were transduced with the VE-cadherin-encoding virus particles. Cells stably expressing VE-cadherin were then selected by FACS on the basis of their GFP expression.

\section{Cell proliferation}

Ep5ExTu cells $\left(10^{5}\right)$ were plated and labeled with bromodeoxyuridine (BrdU) in 96-well plates in DMEM-F12 supplemented with $15 \%$ FCS. After $24 \mathrm{~h}$, cell proliferation was quantified using a colorimetric immunoassay based on BrdU incorporation according to manufacturer's instructions (Roche, Mannheim, Germany). The amount of BrdU incorporated into the cells was measured by using an ELISA plate reader (Plus MS2 Reader, Titertek, Huntsville, AL, USA). For each independent experiment, six wells per condition were used.

\section{RNA isolation and reverse transcription-PCR analysis}

Ep5ExTu cells $\left(2 \times 10^{5}\right)$ were seeded in $4 \mathrm{ml}$ DMEM-F12 supplemented with $15 \%$ FCS in $6 \mathrm{~cm}$ dishes $24 \mathrm{~h}$ before RNA isolation. Total RNA was isolated from cell lysates using a universal RNA Purification Kit according to the manufacturer's protocol (Roboklon, Berlin, Germany). Aliquots of $3 \mu \mathrm{g}$ of total RNA were reverse transcribed using Superscript II (Invitrogen, Karlsruhe, Germany) and random hexameric primers (Roche, Mannheim, Germany). The sequences of the PCR primers used are shown in Additional file 1. The intensity of the PCR bands was quantified using Bio-Rad densitometer and Quantity One analysis software (Hercules, CA, USA). qRT-PCR analysis for human VE-cadherin and N-cadherin was performed following reverse transcription of total RNA using a Reverse Transcriptase Core Kit (Eurogentec, Seraing, Belgium), by real-time PCR (Mastercycler ep Realplex; Eppendorf, Hamburg, Germany) using QuantiFast SYBR Green PCR Kit (Qiagen, Valencia, CA, USA). All reactions were run in duplicates and $\mathrm{Ct}$ values were normalized against the GAPDH gene, using the delta-delta-Ct method. Primer sequences used were: VEcadherin (CDH5), (forward) 5'-CGT GAG CAT CCA GGC AGT GGT AGC-3', (reverse) 5'-GAG CCG CCG CCG CAG GAA G-3'; N-cadherin (CDH2) (forward) 5'CCA CCT TAA AAT CTG CAG GC-3', (reverse) 5'GTG CAT GAA GGA CAG CCT CT-3'; GAPDH, (forward) 5'-CTC CTC TGA CTT CAA CAG CGA CA-3', (reverse) 5'-GAG GGT CTC TCT CTT CCT CTT GT-3'.

\section{Immunoblot analysis}

Immunoblot analysis was performed as described previously $[7,26,27]$. The primary antibodies used were anti-VE-cadherin (R\&D Systems, Wiesbaden, Germany), anti-N-cadherin and anti- $\beta$-actin (Sigma-Aldrich, Munich, Germany). The secondary antibodies were horseradish peroxidase-conjugated anti-rabbit immunoglobulin G (IgG) (Novus Biologicals, Littleton, CO, USA), anti-goat IgG (Jackson Immunoresearch, Soham, UK) and anti-mouse IgG (Cell Signaling Technology, Frankfurt, Germany). Band intensity was quantified using Quantity One analysis software (Bio-Rad, Hercules, CA, USA). Antibodies used for detection of human VE-cadherin, $\mathrm{N}$-cadherin and $\mathrm{E}$-cadherin were goat anti-VE-cadherin (Santa Cruz Biotechnology, Santa Cruz, CA, USA), mouse anti-N-cadherin (BD Biosciences, Bedford, MA, USA), mouse anti-E-cadherin (BD Biosciences, Bedford, MA, USA). Membranes were incubated with secondary antibody conjugated with IRDye Infrared Dyes (IRDYE 800CW donkey anti-goat, IRDYE $800 \mathrm{CW}$ donkey anti-mouse), and bands were revealed with a LI-COR scanner (LI-COR Biosciences, Lincoln, NE, USA).

\section{Immunofluorescence staining of cells}

Cells $\left(2 \times 10^{5}\right)$ were seeded on glass coverslips. After $24 \mathrm{~h}$, cells were fixed as described [7] and stained with the following primary antibodies: anti-VE-cadherin (R\&D 
Systems, Wiesbaden, Germany), anti-N-cadherin (BD Biosciences, Bedford, MA, USA), anti-E-cadherin (SigmaAldrich, Munich, Germany), anti- $\beta$-catenin (Cell Signaling Technology, Frankfurt, Germany) and anti-Vimentin (Sigma-Aldrich, Munich, Germany). The secondary antibodies used were goat anti-rat Alexa 594, chicken antirabbit Alexa 594 and rabbit anti-goat 594 (Molecular Probes, Leiden, The Netherlands). Antibodies used for detection of human VE-cadherin, N-cadherin and E-cadherin were: goat anti-VE-cadherin (Santa Cruz Biotechnology, Santa Cruz, CA, USA), mouse anti-N-cadherin (BD Biosciences, Bedford, MA, USA), mouse anti-E-cadherin (BD Biosciences, Bedford, MA, USA).

\section{Tumor experiments}

Ep5ExTu cells were cultured in DMEM-F12 supplemented with $15 \%$ FCS. Cells were then trypsinized, rinsed twice in $5 \mathrm{ml}$ PBS and resuspended in PBS at a concentration of $1 \times 10^{6}$ cells $/ \mathrm{ml}$. Tumor experiments were performed as described previously [27] with eight- to twelve-week-old female BALB/c mice (Taconic, Ejby, Denmark). All tumors were measured with calipers every two to three days and the volume of each measurement was calculated as: (width ${ }^{2} \times$ length)/2. Tumors were collected 10 or 15 days after injection, embedded in Tissue Tek (Sakura Finetek, Staufen, Germany) and frozen on dry ice. Animal experimentation was approved by the Landesdirektion Dresden, Germany (Re: 24-9168.11-1/ 2009-19).

\section{Immunofluorescence staining of frozen tumor sections}

Eight $\mu \mathrm{m}$ frozen sections were cut and air dried. Sections were then fixed in $100 \%$ acetone for $10 \mathrm{~min}$ at $-20^{\circ} \mathrm{C}$ and air dried. Rehydrated sections were stained with antibodies as described for immunofluorescence staining of cells.

\section{Immunohistochemistry on human tumor tissue microarray}

The tissue microarray included formalin-fixed, paraffinembedded probes of 84 invasive breast cancers. The clinicopathological features are summarized in Additional file 2. Specimens were dewaxed, and immunohistochemical staining was performed using an automated immunostainer according to the manufacturer's protocol (Benchmark; Ventana Medical Systems, Tucson, AZ, USA) as described previously [7]. The primary antibodies were anti-human VE-cadherin and anti-human $\mathrm{N}$-cadherin (Polyclonal; Abcam, Cambridge, UK). The signal was amplified using the VENTANA amplification kit (Benchmark; Ventana Medical Systems, Tucson, AZ, USA) and visualized using avidin-biotin labeling and 3, 3'-diaminobenzidine. Slides were counterstained with hematoxylin. Evaluation of the staining was performed separately for nuclear, cytoplasmic and membrane-associated expression in a semi-quantitative manner. Expression was considered as positive if at least $1 \%$ of the tumor cells were stained. Chi-squared test was used for statistical evaluation of the results, and a $P$ value $<0.05$ was considered as statistically significant. The study was approved by the Ethics Committee (Ethikkommisssion) of the Faculty of Medicine of the University of Dresden (Re: EK59032007).

\section{Results}

$\mathrm{N}$-cadherin and VE-cadherin are co-expressed in human breast cancer tissue

We recently reported that VE-cadherin is aberrantly expressed in approximately $73 \%$ of human invasive mammary carcinomas (27 out of 37 cases). Expression was observed in a subset of tumor cells, as well as in the tumor vasculature. Here, we have extended this analysis by examining a larger number $(n=84)$ of invasive breast cancer specimens in a tissue microarray. This array included carcinomas of different tumor stages, histological types and histopathological grades. The clinicopathological features are summarized in Additional file 2. VE-cadherin protein was detected by immunohistochemistry in a subset of tumor cells in 61 of the $79(77 \%)$ invasive carcinomas examined (Table 1). Yet, we did not observe a significant correlation between VE-cadherin expression and clinicopathological factors (data not shown). $82 \%$ of the tumors expressed $\mathrm{N}$-cadherin protein, and $62 \%$ of the specimens were positive for both VE- and N-cadherin. This result shows for the first time that these two cadherins can be co-expressed in breast cancer (Figure 1). However, the localization of VE- and N-cadherin in tumor cells appears to be partially different (Table 1 ). VE-cadherin membrane staining was observed in 31 tumors (39\%) whereas N-cadherin was localized at the membrane in only 6 breast cancers (7\%). Table 2 summarizes the relationship between $\mathrm{N}$-cadherin expression and the clinicopathological features of the breast cancers: membrane localization of $\mathrm{N}$ -

Table 1 Neural (N)-cadherin and vascular endothelial (VE)-cadherin immunoreactivity in human mammary carcinoma cells.

\begin{tabular}{cccc}
\hline $\begin{array}{c}\text { N-cadherin } \\
\text { expression }\end{array}$ & Positzive & Negative & $\begin{array}{c}\text { Positive expression } \\
\text { percentage }\end{array}$ \\
\hline Membrane & 6 & 78 & $7 \%$ \\
\hline Cytoplasmic & 29 & 55 & $34 \%$ \\
\hline Nuclei & 55 & 29 & $65 \%$ \\
\hline Total expression & 69 & 15 & $82 \%$ \\
\hline $\begin{array}{c}\text { VE-cadherin } \\
\text { expression }\end{array}$ & Positive & Negative & $\begin{array}{c}\text { Positive expression } \\
\text { percentage }\end{array}$ \\
\hline Membrane & 31 & 48 & $39 \%$ \\
\hline Cytoplasmic & 56 & 23 & $70 \%$ \\
\hline Total expression & 61 & 18 & $77 \%$ \\
\hline
\end{tabular}



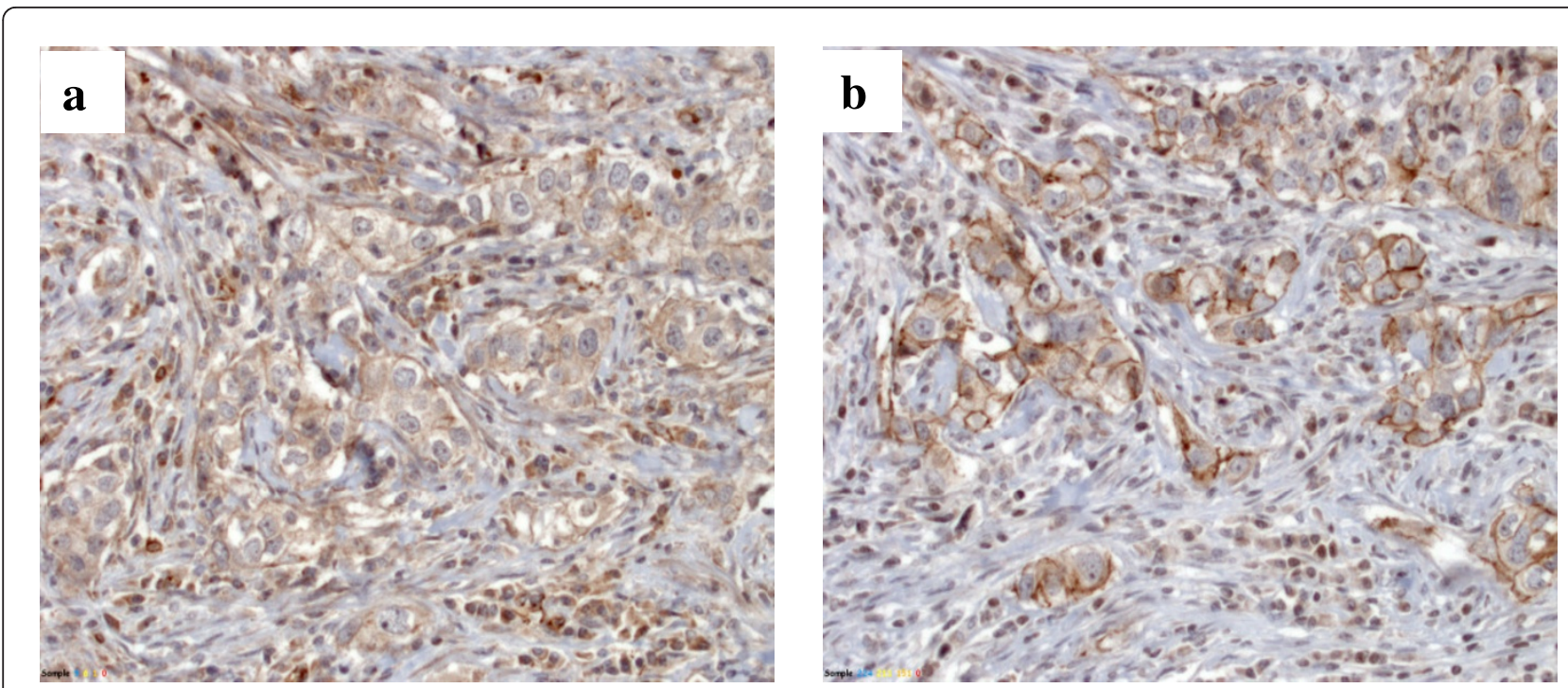

Figure 1 Immunohistochemical staining of vascular endothelial (VE)-cadherin (a) and neural (N)-cadherin (b) in human breast cancer tissue.

cadherin in tumors significantly correlated with smaller tumor size ( 5 out of 36 cases pT1 vs. 1 out of 47 cases pT2, $P=0.04$ ); in contrast, nuclear expression of $\mathrm{N}$ cadherin was observed primarily in poorly differentiated tumors.

\section{$\mathrm{N}$-cadherin knockdown results in reduction of VE- cadherin expression in breast cancer cells}

To investigate the functional role of $\mathrm{N}$-cadherin in breast cancer cells, N-cadherin expression was silenced by transfection of two different siRNAs into Ep5ExTu cells. Unexpectedly, downregulation of N-cadherin in Ep5ExTu cells resulted in reduced VE-cadherin expression (see Additional file 3 ). Next, we stably silenced $\mathrm{N}$-cadherin expression by lentiviral transduction with two different short hairpin RNAs (shRNAs), Sh-Ncad1 and Sh-Ncad2. We selected three independent cell clones (Sh-Ncad1.1,

Table 2 Correlation between neural (N)-cadherin expression and clinicopathological factors.

\begin{tabular}{cccc}
\hline & \multicolumn{4}{c}{ N-cadherin membrane expression } \\
\hline Parameter & Negative & Positive & P value \\
\hline Tumor size $(\mathrm{pT})$ & & & 0.040 \\
1 (Tumor size $\leq 2 \mathrm{~cm})$ & 31 & 5 & \\
2 (Tumor size $>2 \mathrm{~cm})$ & 46 & 1 & \\
\hline \multicolumn{5}{c}{ N-cadherin } & nuclear expression \\
\hline Parameter & Negative & Positive & $P$ value \\
\hline Histopathological Grading & & & 0.006 \\
1 & 7 & 0 & \\
2 & 15 & 25 & \\
3 & 13 & 22 & \\
\hline
\end{tabular}

Sh-Ncad1.2 and Sh-Ncad2) that displayed reduced $\mathrm{N}$-cadherin expression in comparison to the control cell line that had been transduced with a scrambled shRNA (Sh-Scr) (Figure 2a). In Sh-Ncad1.1 and Sh-Ncad2 cells, $\mathrm{N}$-cadherin protein levels were reduced by approximately $75 \%$ as compared to the Sh-Scr cell line, whereas in ShNcad1.2 cells, N-cadherin protein expression was reduced by only $45 \%$. Consistent with the results obtained from the transient transfection with siRNA (see Additional file 3), immunoblot analysis (Figure 2a) and immunofluorescence staining (see Additional file 3) of the cells revealed also a clear reduction in VE-cadherin expression in the $\mathrm{N}$-cadherin knockdown cell lines (Sh-Ncad1.1, Sh-Ncad1.2 and Sh-Ncad2). This result suggests that $\mathrm{N}$-cadherin is required for sustaining the expression of VE-cadherin in Ep5ExTu cells.

In contrast, VE-cadherin silencing by lentiviral transduction of Ep5ExTu cells with shRNA specific for VE-cadherin affected the protein level of $\mathrm{N}$-cadherin only slightly because $\mathrm{N}$-cadherin levels were similar to the ShVE-cadherin cell lines (Sh-VEcad1 and Sh-VEcad2) and the control Sh-Scr cell line (Figure 2b). However, as described for endothelial cells $[28,29]$, VE-cadherin expression affected N-cadherin localization (Figure 2c and [7]). In the Sh-Scr cell line, VE-cadherin was expressed heterogeneously and presented at the cell surface similar to untransfected Ep5ExTu cells, whereas Ncadherin staining was uniformly distributed over the cell and localized at cell-cell contacts in only a few cells (Figure 2c). In cells silenced for VE-cadherin (Sh-VEcad1), $\mathrm{N}$-cadherin was enriched at cell-cell contacts. This shows that silencing of VE-cadherin leads to a redistribution of 


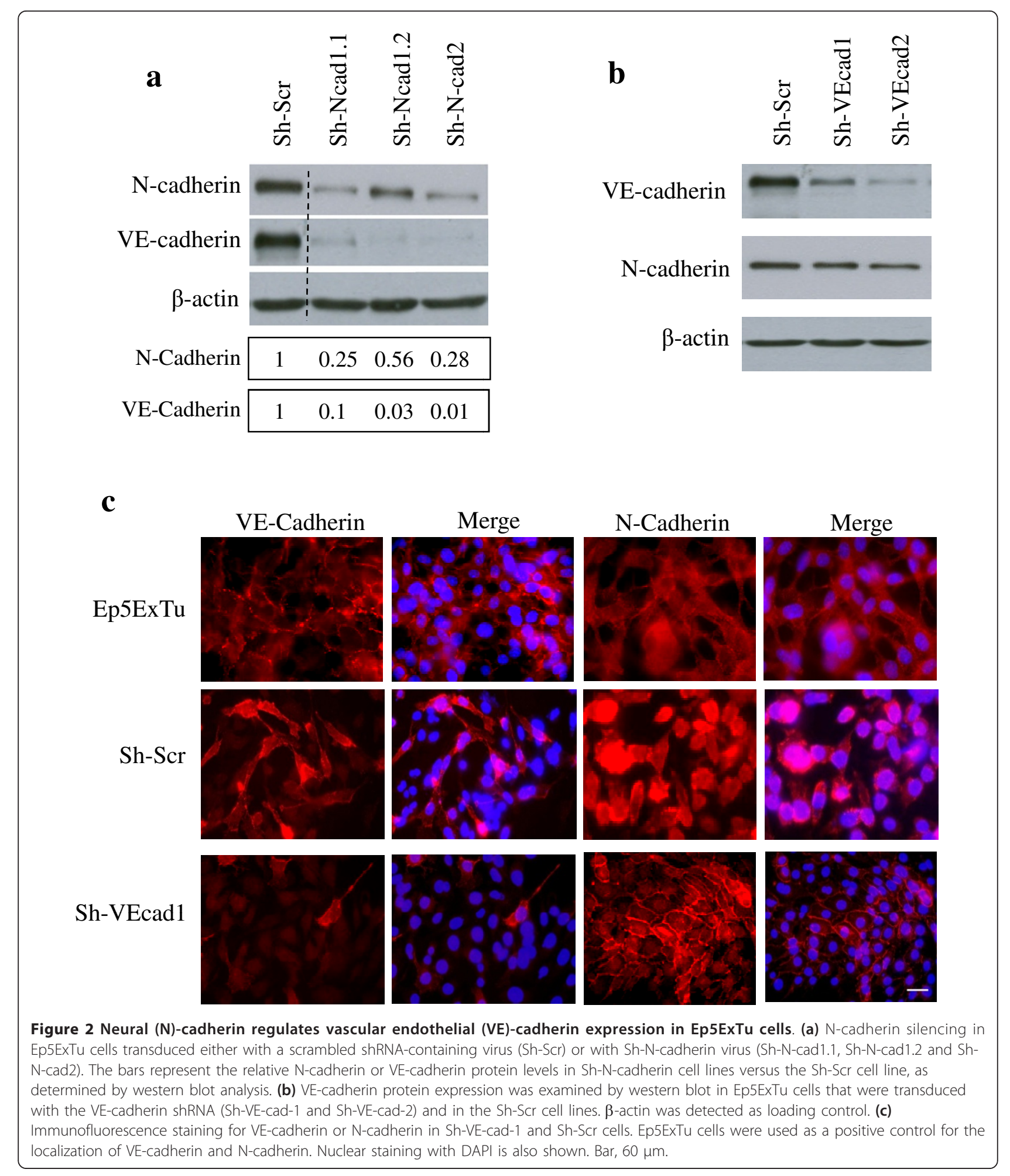

$\mathrm{N}$-cadherin to cell-cell contacts, without influencing its expression levels significantly.

We also investigated the expression of VE-cadherin and $\mathrm{N}$-cadherin in the human breast carcinoma cell line, SUM
149. By western blot analysis, immunofluorescence staining and qRT-PCR, SUM 149 cells expressed VE-cadherin and $\mathrm{N}$-cadherin, in addition to E-cadherin (see Additional File 4). Knockdown of N-cadherin resulted in reduction of 
VE-cadherin mRNA levels but not vice versa. Thus, regulation of VE-cadherin by $\mathrm{N}$-cadherin is observed in both mouse and human breast cancer cells.

\section{Suppression of $\mathrm{N}$-cadherin in mesenchymal Ep5ExTu cells} induces MET and re-expression of E-cadherin

Ep5ExTu cells exhibit fibroblastoid characteristics, such as elongated shape and relatively weak cell-cell contacts as compared to epithelial cells $[7,25,26]$. We have previously observed that E-cadherin is expressed in epithelial Ep5 cells, but not in fibroblastoid Ep5ExTu cells, in agreement with the observation that E-cadherin is downregulated during EMT [7]. The two Ep5ExTu cell lines in which $\mathrm{N}$-cadherin expression was efficiently silenced by shRNA (Sh-Ncad1.1 and Sh-Ncad2), displayed a cobblestone-like appearance characteristic for epithelial cells, with individual cells abutting each other (Figure 3a). Consistent with the idea that these cells have undergone MET, the epithelial phenotype of these Sh-Ncadherin cell lines was associated with re-expression of E-cadherin (Figure $3 \mathrm{~b}$ and $3 \mathrm{c}$ ). Thus, E-cadherin can be re-induced in Ep5ExTu cells by blocking $\mathrm{N}$-cadherin expression. Interestingly, E-cadherin expression was stronger in the Sh-Ncad1.1 and Sh-Ncad2 cell lines than a

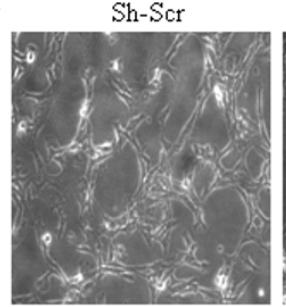

b

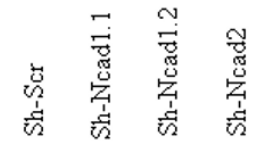

E-cadherin

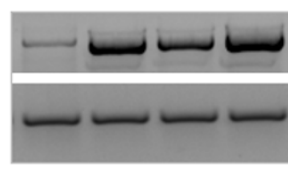

c

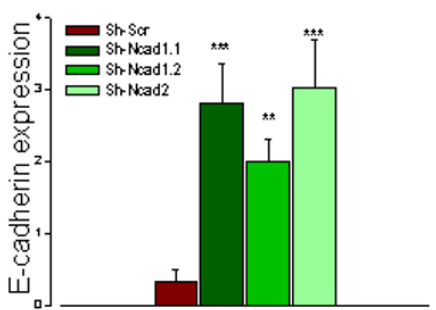

Sh-Ncad1.1
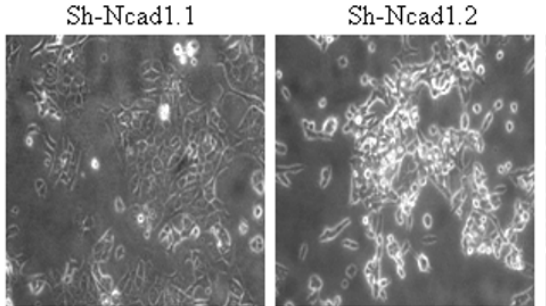

d

E-cadherin

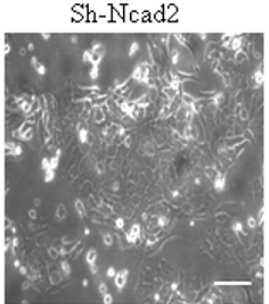

$\underline{\operatorname{Ep} 5}$
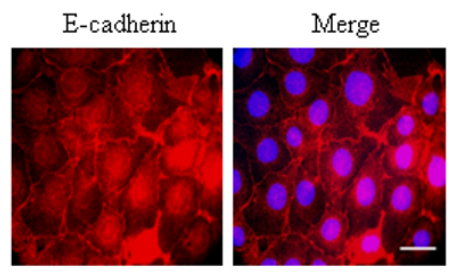

E-cadherin

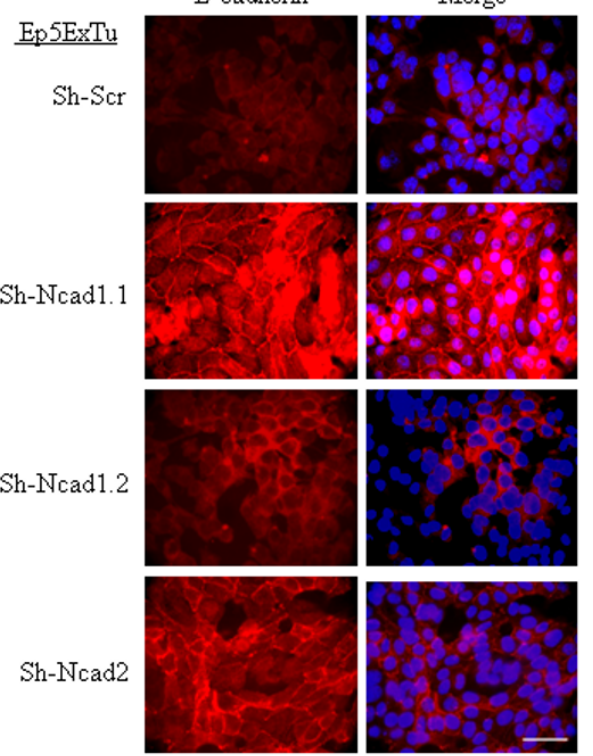

Figure 3 Neural (N)-cadherin silencing in Ep5ExTu cells induced epithelial (E)-cadherin expression and influenced its localization in the cells in a dose-dependent manner. (a) Phase contrast microscopy of control cell lines (Sh-Scr) and Sh-N-cadherin cell lines (Sh-N-cad1.1, Sh-N-cad1.2 and Sh-N-cad2). Bar, 100 m. (b) E-cadherin mRNA levels in Ep5ExTu clones. (c) The graph represents the quantification of the relative amount of E-cadherin mRNA in three independent experiments. $\beta$-actin was used as loading control. The mean \pm SD is indicated. $(n=3)$ $\left(* *, P<0.0012\right.$ and $\left.{ }^{* * *}, P<0.0009\right)$. (d) Immunolocalization of E-cadherin in Ep5 (Bar, $\left.30 \mu \mathrm{m}\right)$ and Ep5ExTu (Bar, $\left.60 \mu \mathrm{m}\right)$ clones by immunofluorescence microscopy. Nuclear staining with DAPI is also shown. 
in the Sh-Ncad1.2 cell line (Figure 3b and 3c), in which $\mathrm{N}$-cadherin expression is only moderately suppressed. Similar to Ep5 cells, E-cadherin staining was observed at sites of cell-cell contacts in both Sh-Ncad1.1 and ShNcad2 cell lines (Figure $3 \mathrm{~d}$ ). These results suggest that the re-induction of E-cadherin in Ep5ExTu cells and its localization at cell-cell contacts correlates with the extent of $\mathrm{N}$-cadherin reduction: the lower the $\mathrm{N}$-cadherin levels are, the more pronounced is the epithelial phenotype. Silencing VE-cadherin in Ep5ExTu cells, in contrast, led to only a partial gain of the epithelial morphology and was not associated with re-induction of E-cadherin (see Additional file 5). This shows that $\mathrm{N}$-cadherin has a more pronounced influence on the maintenance of the mesenchymal tumor cell phenotype than VE-cadherin.
$\mathrm{N}$-cadherin silencing influences $\beta$-catenin localization and the expression of EMT regulator genes in Ep5ExTu cells $\beta$-catenin accumulation in the nuclei of carcinoma cells and transcriptional activation of its target genes are known to take place during malignant transformation, thereby stimulating tumor progression [2,30-33]. E-cadherin can sequester $\beta$-catenin in epithelial cells, thus lowering the amount of cytoplasmic and nuclear $\beta$-catenin, decreasing its transcriptional activity and inhibiting its tumorigenic potential [34]. To investigate whether the localization of $\beta$-catenin in Ep5ExTu breast cancer cells is altered by $\mathrm{N}$-cadherin silencing, we performed immunofluorescence staining. In (epithelial) Ep5 cells, $\beta$ catenin was localized at the plasma membrane (Figure 4a) where also E-cadherin is expressed (Figure 3d). Likewise,

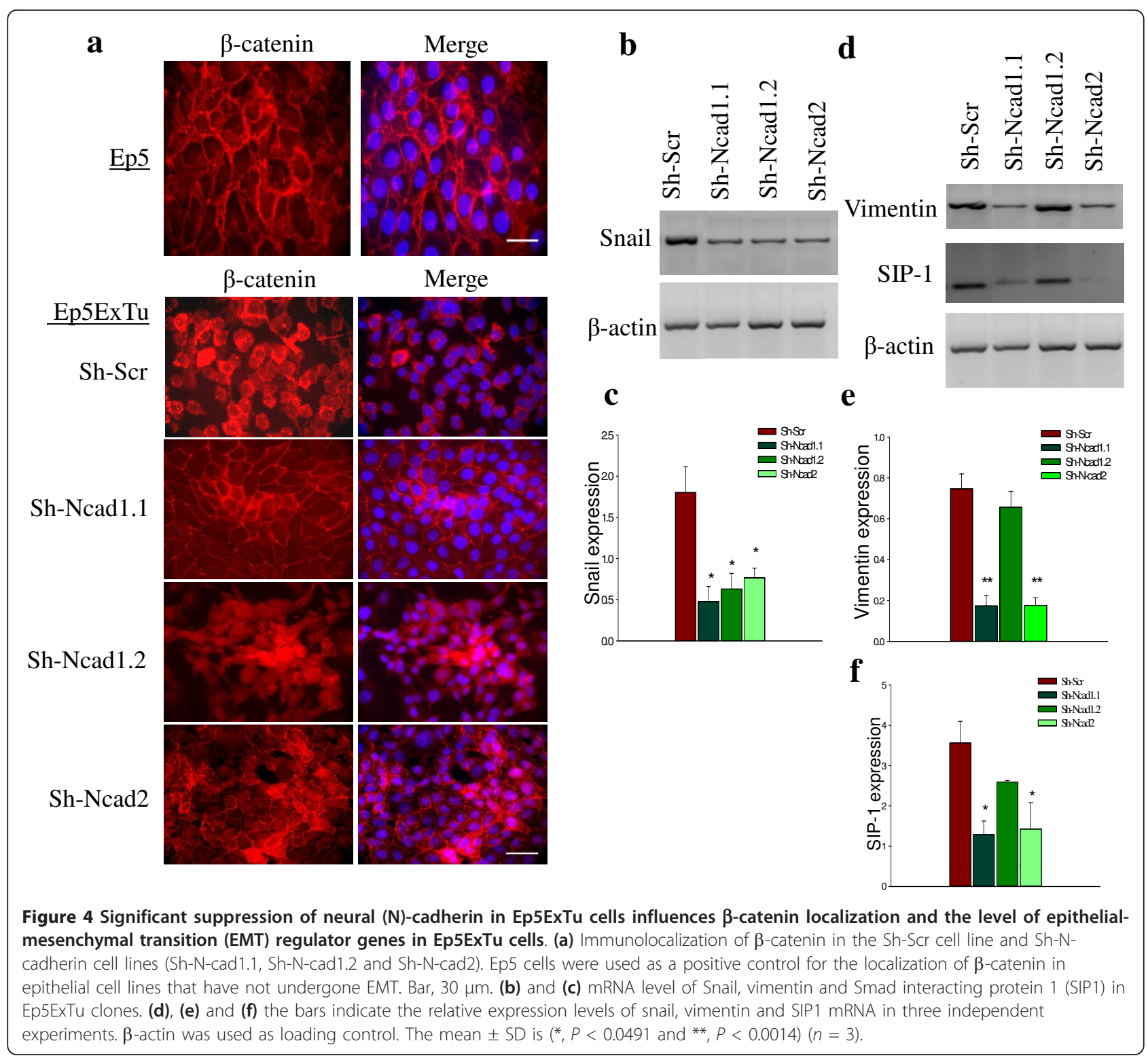


$\beta$-catenin was localized at the plasma membrane along with E-cadherin in the two Sh-N-cadherin cell lines that had greatly reduced $\mathrm{N}$-cadherin (Sh-Ncad1.1 and Sh-Ncad2) (Figure 3d, Figure 4a). In contrast, clone ShNcad1.2, which had moderately reduced N-cadherin, and clone Sh-VE-cadherin showed no significant differences in $\beta$-catenin localization compared to the Sh-Scr control cell line (Figure 4a and Additional file 6), and we observed localization of $\beta$-catenin to cell-cell contacts in only a few cells. Together, these results show that efficient silencing of $\mathrm{N}$-cadherin in mesenchymal murine mammary carcinoma cells leads to the re-expression of E-cadherin and the co-localization of this receptor with $\beta$-catenin at the plasma membrane.

Nuclear localization of $\beta$-catenin and the expression of vimentin are involved in epithelial-to-mesenchymal transition and correlate with enhanced invasive and migratory properties of cells $[24,35]$. Because $\beta$-catenin can stimulate vimentin expression [36], we tested whether the recruitment of $\beta$-catenin to the cell membrane of the $\mathrm{N}$-cadherin knockdown cell lines is correlated with changes in the expression of EMT-related genes. The expression of the transcription factor Snail was reduced in all Sh-N-cadherin cell lines as compared to the control cell line (Figure $4 \mathrm{~b}$ and $4 \mathrm{~d}$ ), whereas the expression of Smad interacting protein-1 (SIP1) and vimentin, which are involved in EMT [37], was downregulated only in Sh-Ncad1.1 and ShNcad2 cell lines (Figure 4c-f and Additional file 6). Whether or not vimentin and SIP1 expression is regulated by $\mathrm{N}$-cadherin remains to be determined.

\section{Efficient silencing of $\mathrm{N}$-cadherin in Ep5ExTu cells inhibits tumor growth in vivo without affecting cell proliferation in vitro}

We have previously shown that silencing VE-cadherin leads to reduced Ep5ExTu cell proliferation and tumor growth [7]. To determine if $\mathrm{N}$-cadherin downregulation has a similar effect, we evaluated the proliferation of Sh$\mathrm{N}$-cadherin cell lines in vitro by BrdU staining. Sh-VEcad2 and Sh-Ncad1.2 cells displayed lower proliferation rates than the control cell line, whereas the proliferation rate of Sh-Ncad1.1 and Sh-Ncad2 cells was not reduced (Figure 5a). To study the effect of N-cadherin on tumor growth, each of the three Sh-N-cadherin cell lines and the control cell line (Sh-Scr) were injected subcutaneously into BALB/c mice. All Sh-N-cadherin cell lines grew significantly slower than the control cell line (Figure 5b). Notably, the Sh-Ncad1.1 and Sh-Ncad2 cell lines, which showed the strongest reduction of $\mathrm{N}$-cadherin expression, hardly grew in vivo. The Sh-Ncad1.2 cell line showed an intermediate growth rate, similar to the Sh-VE-cadherin cell line (Figure 5c). These data show that a strong (approximately $75 \%$ ) reduction of $\mathrm{N}$-cadherin expression in Ep5ExTu cells is necessary to inhibit tumor growth efficiently. To perform a histological analysis of tumor tissue, we isolated tumors at day 10 post injection. Downregulation of $\mathrm{N}$-cadherin and $\mathrm{VE}$-cadherin expression in the Sh-Ncad1.2 and Sh-Ncad2 tumors was confirmed by immunofluorescence staining (see Additional file 7). Ecadherin staining was only visible in the Sh-N-cadherin tumors (Figure 5d), and was more intense in Sh-Ncad2 than in Sh-Ncad1.2 tumors. Because vimentin expression has been implicated in carcinogenesis $[38,39]$, we also examined the expression of this intermediate filament in the different experimental tumor groups. Vimentin expression was strongly reduced only in the Sh-Ncad2 cell line (Figure $5 \mathrm{~d}$ ). Taken together, our results suggest that both re-induction of E-cadherin expression and downregulation of vimentin expression contribute to tumor growth inhibition resulting from $\mathrm{N}$-cadherin silencing in Ep5ExTu cells.

\section{Forced expression of VE-cadherin in $\mathrm{N}$-cadherin deficient tumor cells does not enhance cell proliferation in vitro or tumor growth}

Because N-cadherin silencing in Ep5ExTu cells also led to a reduction of VE-cadherin expression, and VE-cadherin silencing inhibited tumor growth, we wanted to determine whether the loss of VE-cadherin contributes to the tumor growth inhibition resulting from silencing $\mathrm{N}$-cadherin. To address this question, we determined whether the forced expression of VE-cadherin in Sh-Ncad2 cells can affect tumor growth of $\mathrm{N}$-cadherin-deficient cancer cells. A lentiviral expression vector encoding VE-cadherin was therefore introduced into Sh-Ncad2 cells. Two independent clones (N-cadVE1 and N-cadVE2) showed VE-cadherin expression levels similar to that of the Sh-Scr cell line (Figure 6a). The forced expression of VE-cadherin had no influence on cell morphology (see Additional file 8), and the expression of $\mathrm{N}$-cadherin and vimentin in $\mathrm{N}$-cadVE1 and N-cadVE2 cells remained unchanged (Figure 6b). These results suggest that expression of VE-cadherin in the absence of N-cadherin cannot induce Sh-Ncad2 cells to undergo EMT.

Next, we explored whether forced expression of VEcadherin can influence cell proliferation. No significant difference in cell proliferation was observed between the VE-cadherin-expressing cell lines (N-cadVE1 and NcadVE2) and control cell line (Sh-Ncad2) (see Additional file 8). To evaluate whether forced VE-cadherin expression influences the growth of Sh-N-cad2 tumors, we inoculated cells from the VE-cadherin-expressing lines (N-cadVE1 and N-cadVE2), Sh-N-cad2 or control Sh-Scr cell lines into wild-type BALB/c mice and monitored tumor growth. The VE-cadherin-expressing cell lines (N-cadVE1 and NcadVE2) and Sh-Ncad2 displayed comparable growth rates and scarcely grew in vivo (Figure 6c). These results show that forced VE-cadherin expression cannot accelerate 
a

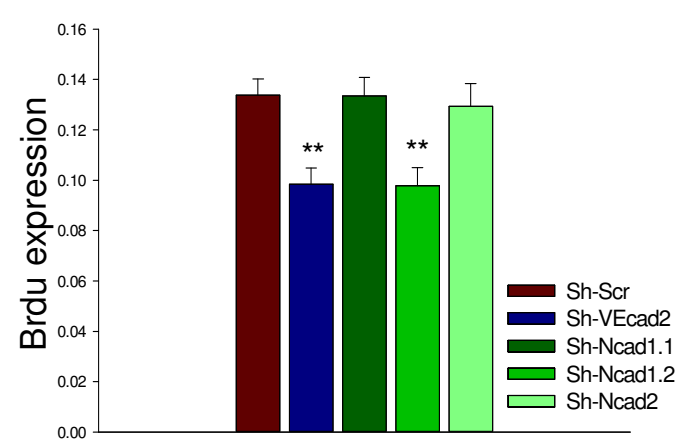

c

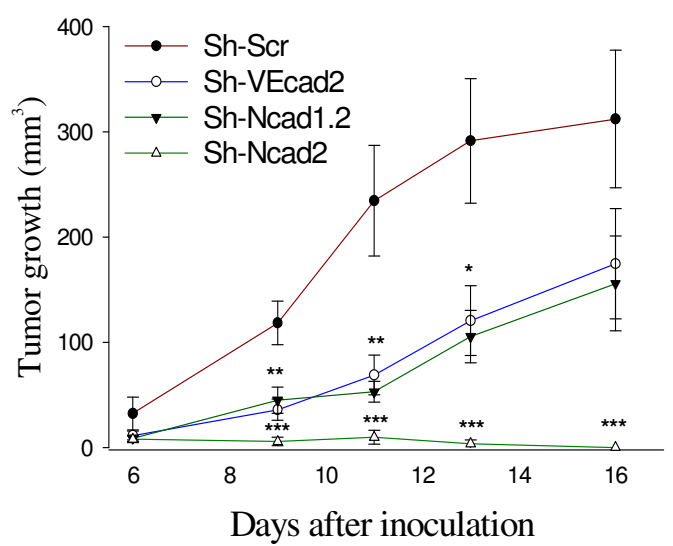

b

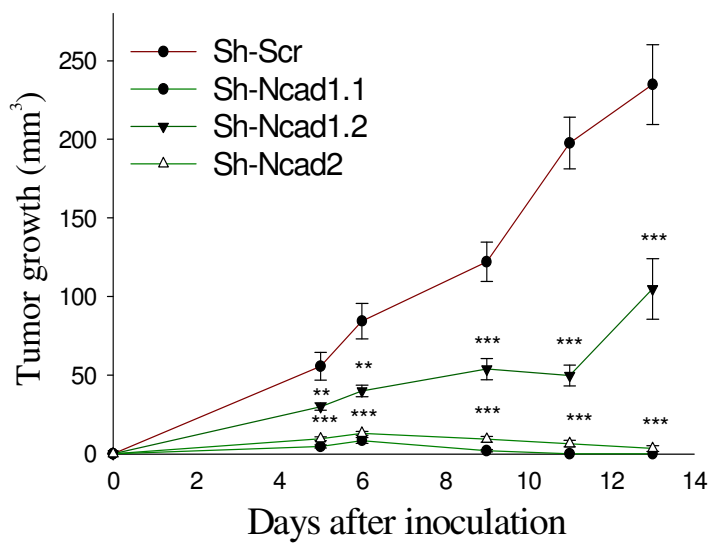

d
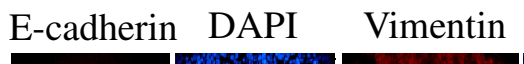

DAPI

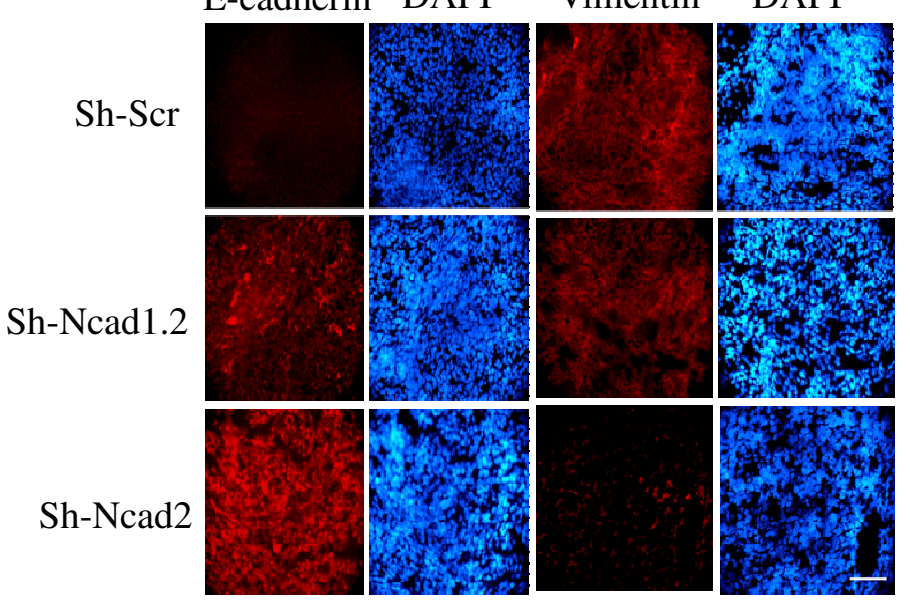

Figure 5 The efficient suppression of neural (N)-cadherin in Ep5ExTu cells inhibits tumor growth in vivo without affecting cell proliferation in vitro. (a) Twenty-four hours after seeding equal numbers of cells, cell proliferation was quantified by measuring bromodeoxyuridine (BrdU) incorporation. The mean \pm SD is (**, $P<0.0010)(n=12)$. (b) Sh-N-cadherin cell lines (Sh-N-cad1.1, Sh-N-cad1.2 and Sh-N-cad2) or Sh-Scr were injected subcutaneously into BALB/C mice. (**, $P<0.0075$ and $\left.{ }^{* * *}, P<0.0001\right)(n=10)$. (c) Sh-N-cadherin cell lines (Sh-N-cad1.2 and Sh-N-cad2), Sh-VE-cadherin cell line (Sh-VE-cad-2) or Sh-Scr cell line injected into BALB/C mice. The mean \pm SD is indicated (*, $P$ $\left.<0.334 ;{ }^{* *}, P<0.0083 ;{ }^{* *}, P<0.0001\right)(n=8)$. (d) Immunofluorescence staining for epithelial (E)-cadherin and vimentin on tumor sections. Nuclear staining with DAPI is also shown. Bar, $100 \mu \mathrm{m}$.

tumor growth in the absence of $\mathrm{N}$-cadherin expression, indicating that the concomitant loss of VE-cadherin expression does not contribute to the reduction of tumor growth resulting from $\mathrm{N}$-cadherin silencing.

Forced VE-cadherin expression in Ep5ExTu cells does not affect E-cadherin localization

Since the localization of VE-cadherin within adherens junctions is required for its function [5], we examined the possibility that the inappropriate localization of VE-cadherin is responsible for its inability to restore tumor growth of $\mathrm{N}$ cadherin-deficient cells. By immunofluorescence staining, VE-cadherin expression was observed at the cell borders in N-cadVE1 cells, similar to control Sh-Scr cells (Figure 7). E-cadherin was also localized at cell-cell junctions as in the
Sh-Ncad2 control cell line (Figure 7). This shows that VEcadherin cannot displace E-cadherin from the cancer cell surface.

\section{Discussion}

Breast cancer is one the leading causes of death due to cancer worldwide. Although the genetic defects underlying breast carcinogenesis have been extensively studied, important signaling pathways involved in the progression of this specific tumor type are still poorly characterized. The loss of E-cadherin and concomitant gain of $\mathrm{N}$-cadherin expression is known to promote EMT and carcinoma progression. Our previous observation that endothelial cell-selective VEcadherin is expressed aberrantly in breast cancer cells and promotes their proliferation both in vitro and in vivo [7] led 


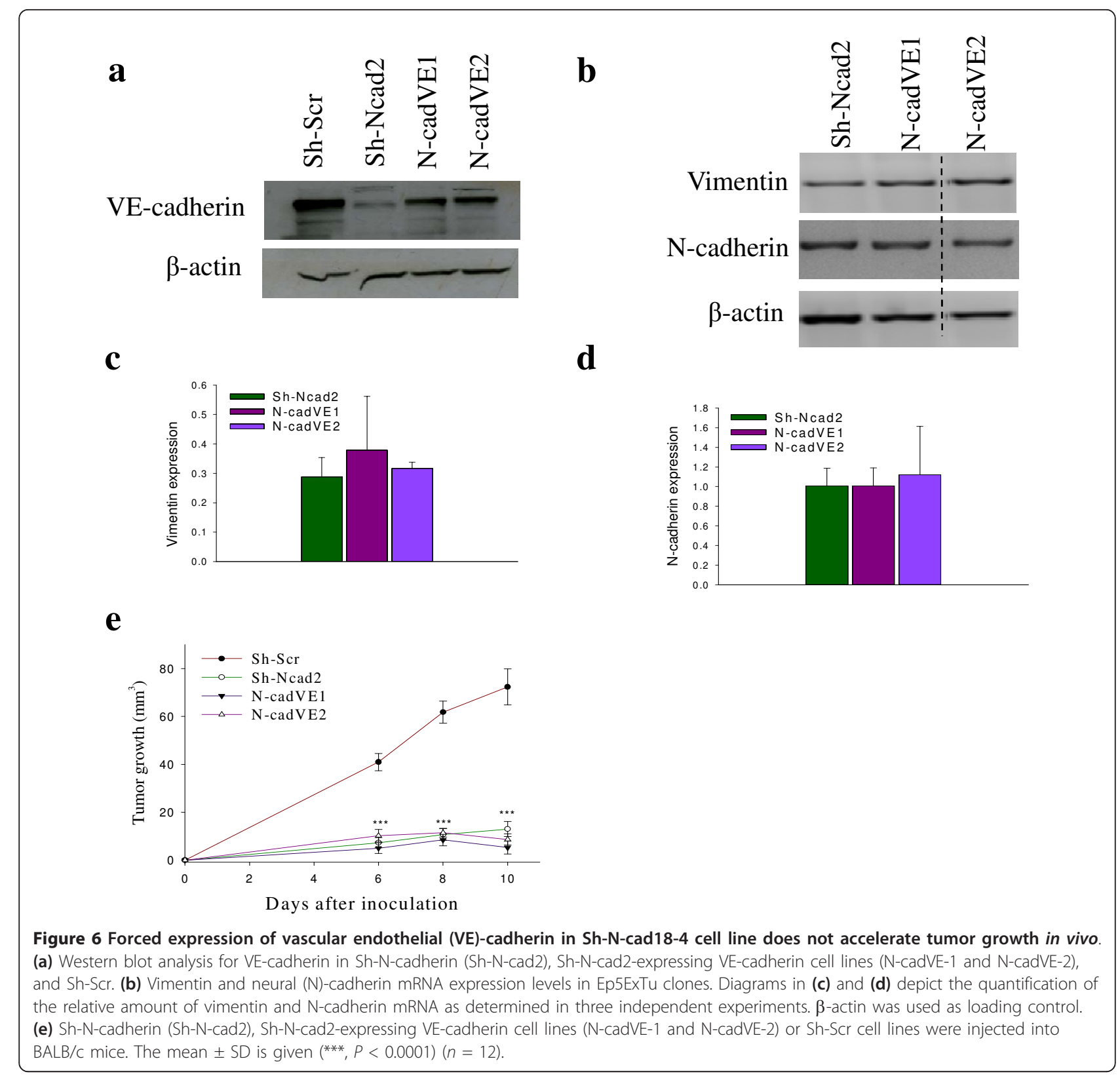

us to analyze the specific roles of these cadherins as well as their interplay in experimental breast cancer in more detail. Here, we show that $\mathrm{N}$-cadherin silencing in murine breast cancer cells suppresses tumor growth by upregulating Ecadherin, repressing EMT regulators, and reversing the invasive mesenchymal phenotype to epithelial phenotype. Although both $\mathrm{N}$-cadherin and VE-cadherin promote tumor growth, their influence on E-cadherin expression in mesenchymal tumor cells is divergent: whereas N-cadherin is capable of repressing E-cadherin expression in Ep5ExTu cells, VE-cadherin has no effect on its expression levels [7]. Moreover, $\mathrm{N}$-cadherin is required for maintaining VE-cadherin expression, but not vice versa. The regulation of VE- cadherin expression by $\mathrm{N}$-cadherin is a novel mechanism of tumor progression in breast cancer and shows that $\mathrm{N}$ cadherin both inhibits the expression of E-cadherin and stimulates the expression of VE-cadherin.

The downregulation of VE-cadherin in the N-cadherindeficient Ep5ExTu cells shows that N-cadherin is required (although not necessarily sufficient) for VE-cadherin expression in aggressive carcinoma cells. Regulation of VE-cadherin by $\mathrm{N}$-cadherin was already described before in (nonmalignant) human umbilical vein endothelial cells (HUVEC) [40], however, evidence for direct regulation of VE-cadherin by $\mathrm{N}$-cadherin is lacking, and the precise mechanisms involved in this regulation remain to be 


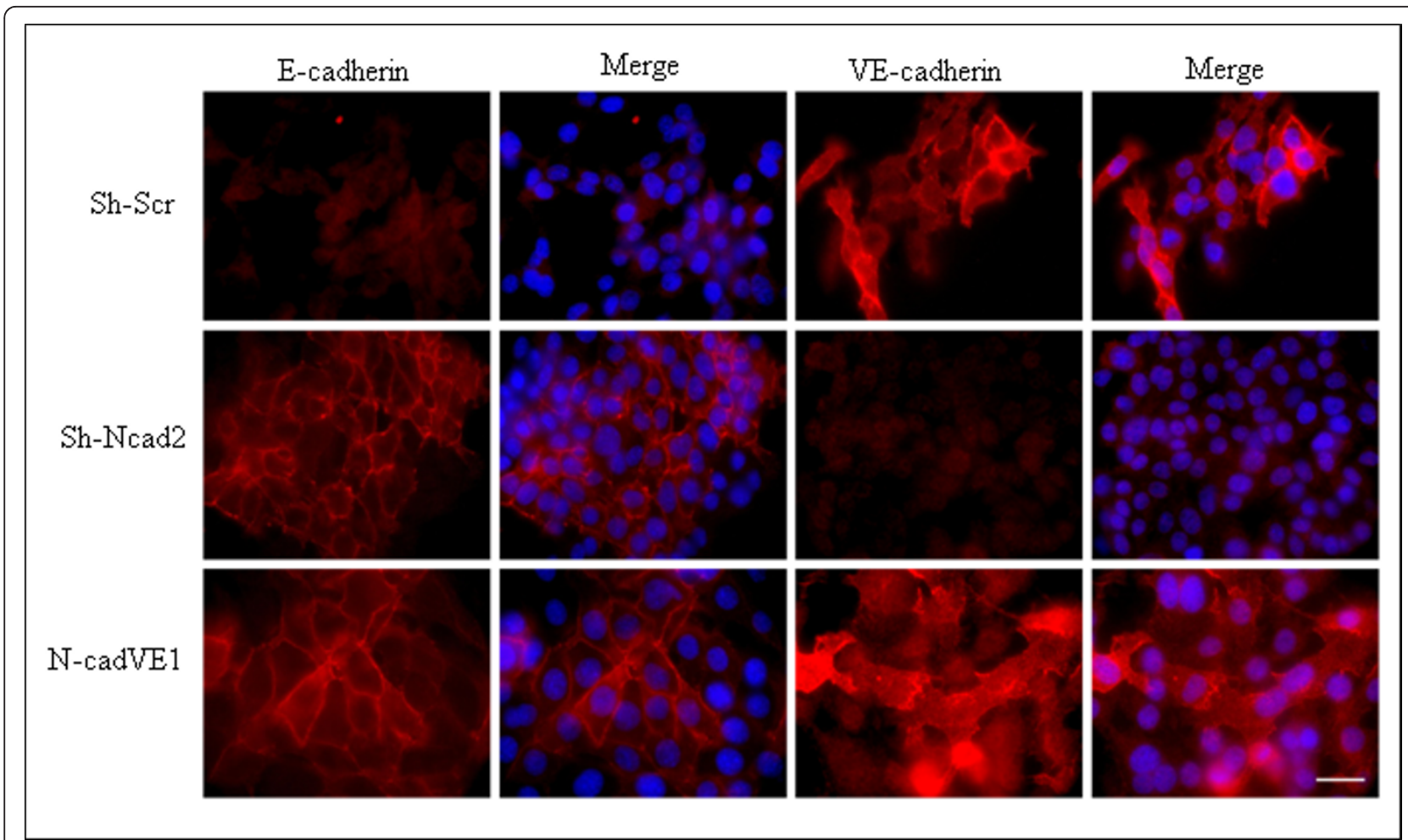

Figure 7 Vascular endothelial (VE)-cadherin expression in Sh-N-cad2 has no influence on epithelial (E)-cadherin localization Immunofluorescence staining for E-cadherin and VE-cadherin in the Sh-N-cadherin cell line (Sh-N-cad2) and in Sh-N-cad2 cell lines expressing VE-cadherin (N-cadVE-1). Ep5ExTu cells were used as positive control for VE-cadherin and neural (N)-cadherin localization. Nuclear staining with DAPI is also shown. Bar, $30 \mu \mathrm{m}$.

determined. The ability of N-cadherin to regulate VE-cadherin was nonreciprocal because VE-cadherin silencing had no effect on N-cadherin expression. However, as described also for other cell types [28,29], VE-cadherin expression in Ep5ExTu cells affected the localization of Ncadherin protein. In control Ep5ExTu cells, which express both cadherins, $\mathrm{N}$-cadherin displayed a nonjunctional distribution whereas in Sh-VE-cadherin knockdown cell lines, $\mathrm{N}$-cadherin was enriched at cell-cell junctions. Whether VE-cadherin expression can influence signaling pathways regulated by $\mathrm{N}$-cadherin as a consequence of excluding it from cell contacts remains to be determined.

There is growing evidence indicating that EMT is a reversible process in cancer cells. Recently, it was hypothesized that tumor cells in metastatic sites can undergo redifferentiation and undergo MET $[1,3,6]$. This transition could allow metastatic cells to adapt to a new microenvironment. Re-expression of E-cadherin is a critical component of the MET [41,42]. However, little is known about the exact mechanism and biological or clinical significance of MET in cancer. Islam et al. reported that blocking Ncadherin expression upregulates E-cadherin expression in squamous epithelial cells [10]. Interestingly, we observed that $\mathrm{N}$-cadherin silencing promoted multiple aspects of
MET in Ep5ExTu cells in a concentration-dependent manner, including morphological changes, increased levels of E-cadherin and decreased levels of mesenchymal markers. In contrast, VE-cadherin silencing led only to a weaker induction of epithelial markers and had no effect on Ecadherin expression, indicating that MET is activated more efficiently by $\mathrm{N}$-cadherin silencing than by VE-cadherin silencing. This difference might be explained by the difference in $\beta$-catenin localization in Sh-N-cadherin and ShVE-cadherin cell lines. Interestingly, in Sh-N-cadherin cell lines (Sh-Ncad1.1 and Sh-Ncad2) that displayed the most efficient $\mathrm{N}$-cadherin downregulation, $\beta$-catenin was localized at the cell membrane like in the epithelial Ep5 cell line. As reported by other groups, alteration of $\beta$-catenin localization alone can be sufficient for the suppression of an invasive phenotype $[24,43]$.

The intermediate filament vimentin is an important marker of EMT and its expression is related to the adhesion and migration properties of tumor cells [44]. A previous study using human breast cancer cells showed that accumulation of cytoplasmic or nuclear $\beta$-catenin and vimentin expression coincide [36]. Additionally, $\beta$-catenin can directly transactivate vimentin expression through its binding to the $\mathrm{T}$ cell factor (TCF)/lymphoid enhancer 
factor (LEF) 1 transcription factor family. Vimentin expression was consistently downregulated in mammary carcinoma cell lines in which $\beta$-catenin was localized at the plasma membrane (Sh-Ncad1.1 and Sh-Ncad2), but vimentin levels remained unchanged in lines that that showed cytoplasmic and/or nuclear distribution of $\beta$-catenin (Sh-Ncad1.2 and Sh-VEcad1).

Several transcriptional regulators are known to repress E-cadherin expression and thereby induce EMT. Among these, we analyzed the expression level of Snail and SIP1, which emerged as key factors regulating E-cadherin expression [45]. Whereas the level of Snail was downregulated in all Sh-N-cadherin cell lines, the level of SIP1 was decreased only in the Sh-Ncad1.1 and Sh-Ncad2 cell lines, which expressed higher E-cadherin levels. This result therefore suggests that the re-expression of E-cadherin is stimulated more efficiently if the expression of both transcriptional repressors of E-cadherin is decreased.

Deregulation of E-cadherin in breast cancer correlates with higher tumor grade and metastatic tumor cell behavior [46,47]. Also in other cell types and in animal models, E-cadherin has been shown to act as a suppressor of tumor growth and invasion [48]. In our study, suppressing $\mathrm{N}$-cadherin significantly reduced Ep5ExTu tumor growth. Remarkably, Sh-Ncad1.1 and Sh-Ncad2 cell lines hardly grew in vivo, and mice injected with either cell line were often tumor-free 14 days after inoculation. Histological analysis of tumor sections isolated at day 10 post injection confirmed the re-expression of E-cadherin and downregulation of vimentin in Sh-Ncad2 tumors in vivo. Since Ncadherin silencing did not change the proliferation rate of Sh-Ncad1.1 and Sh-Ncad2 in vitro, it is likely that the phenotypic reversion of these cell lines, along with E-cadherin expression and associated $\beta$-catenin, leads to the inhibition of tumor growth in vivo. In contrast, moderate suppression of N-cadherin in Sh-Ncad1.2, which greatly inhibits VE-cadherin expression, resulted in a growth rate similar to the Sh-VEcad2 cell line. This growth inhibition correlates well with the decrease in cell proliferation observed for both cell lines in vitro. It is therefore possible that the growth inhibition of the Sh-Ncad1.2 cell line is caused primarily by the strong VE-cadherin suppression.

Does the introduction of VE-cadherin in N-cadherin (and consequently VE-cadherin) deficient cells restore tumor growth? The forced expression of VE-cadherin in the Sh-Ncad2 cells (that had undergone MET) did not change their epithelial phenotype, as indicated by unchanged E-cadherin and vimentin expression levels. Additionally, junctional localization of E-cadherin was preserved in VE-cadherin re-expressing cell lines. In line with the unaltered epithelial phenotype, forced expression of VE-cadherin failed to evoke a significant difference in tumor growth; the VE-cadherin-expressing and control cells had similar growth rates in vivo. These results suggest that VE-cadherin expression, at least in the presence of E-cadherin, is not sufficient to promote tumor progression.

\section{Conclusions}

Our study shows for the first time that $\mathrm{N}$-cadherin and VE-cadherin are co-expressed in human breast cancer. Ncadherin controls the expression of VE-cadherin in aggressive mouse breast cancer cells and has an important role in maintaining the mesenchymal phenotype and promoting tumor progression. VE-cadherin, on the other hand, regulates the subcellular localization of $\mathrm{N}$-cadherin by displacing it from the cell surface. Our study supports the hypothesis that the interplay between cadherins in breast cancer progression is not limited to the classical 'cadherin switch', which involves the loss of E-cadherin expression or function and the gain of N-cadherin, but comprises also an intricate interdependence of $\mathrm{N}$-cadherin and VEcadherin.

\section{Additional material}

\section{Additional file 1: List of PCR primers}

Additional file 2: Histological types and histopathological grades of invasive human breast carcinomas.

Additional file 3: Expression of VE-cadherin and neural (N)-cadherin in $\mathrm{N}$-cadherin-silenced tumor cells.

Additional file 4: Expression of classical cadherins in the human breast cancer cell line SUM 149.

Additional file 5: Morphology and epithelial (E)-cadherin immunofluorescence staining of Sh-VE-cadherin and control cell lines.

Additional file 6: Immunofluorescence staining of $\beta$-catenin in ShVE-cadherin and Sh-Ncad2 cell lines.

Additional file 7: Immunofluorescence staining of neural (N)cadherin and vascular endothelial (VE)-cadherin on tumor sections.

Additional file 8: Morphology and proliferation analysis of vascular endothelial (VE)-cadherin-overexpressing Sh-Ncad2 cells.

\section{Abbreviations}

BrdU: bromodeoxyuridine; DMEM: Dulbecco's modified Eagle's medium; E-cadherin: epithelial cadherin; EMT: epithelial-mesenchymal transition; FACS: fluorescence-activated cell sorting; FCS: fetal calf serum; GFP: green fluorescent protein; HUVEC: human umbilical vein endothelial cells; lgG: immunoglobulin G; MET: mesenchymal-epithelial transition; N-cadherin: neural cadherin; PBS: phosphate-buffered saline; PCR: polymerase chain reaction; shRNA: small hairpin ribonucleic acid; siRNA: small interfering RNA; SIP1: Smad interacting protein 1; TGF- $\beta$ : transforming growth factor-beta; VE-cadherin: vascular endothelial cadherin.

\section{Acknowledgements}

We would like to thank Prof. Dirk Lindemann for kindly providing viral expression vectors, Anke Klawitter for expert technical assistance, Merle Mechlinski and Dr. Marion Leick for help with detection of human cadherins and QRT-PCR, and Dr. Laurel Rohde for critical reading of the manuscript.

This work was supported by grants of the Deutsche Forschungsgemeinschaft (DFG-Br 1336/3-1 and 3-2 to GB) and the Bundesministerium für Bildung und Forschung (BMBF). 


\section{Author details}

'Department of Pathology, University of Dresden, Fetscherstrasse 74, D-01307 Dresden, Germany. ${ }^{2}$ Emmy-Noether Research Group, Department of Pathology, University of Dresden, Fetscherstrasse 74, D-01307 Dresden, Germany. ${ }^{3}$ Koch Institute for Integrative Cancer Research, 500 Main Street, Massachusetts Institute of Technology, Cambridge, MA 02139, USA. ${ }^{4}$ Department of Anatomy, University of Münster, Vesaliusweg 2-4, D-48149 Münster, Germany. ${ }^{5}$ Present address: Department of Biomedicine, University of Basel, Mattenstrasse 28, CH-4058 Basel, Switzerland.

\section{Authors' contributions}

MR participated in the design of the project, performed the majority of in vitro experiments, analyzed the experimental tumors, and drafted the manuscript. KF helped to obtain human breast tumors and conducted tumor histology analysis. BW performed tumor experiments. AKu and AKe helped to perform in vitro experiments and analyses of experimental tumors. $\mathrm{ML}$ and GBa participated in the design of the project. HS helped to analyze expression of VE-cadherin in human cells. GB conceived the study, participated in its design and coordination and helped to draft the manuscript. All authors read and approved the final manuscript.

\section{Competing interests}

The authors declare that they have no competing interests.

Received: 26 June 2012 Revised: 8 November 2012

Accepted: 20 November 2012 Published: 6 December 2012

\section{References}

1. Hazan RB, Qiao R, Keren R, Badano I, Suyama K: Cadherin switch in tumor progression. Ann NY Acad Sci 2004, 1014:155-163.

2. Christofori G, Semb H: The role of the cell-adhesion molecule E-cadherin as a tumour-suppressor gene. Trends Biochem Sci 1999, 24:73-76.

3. Wheelock MJ, Shintani Y, Maeda M, Fukumoto Y, Johnson KR: Cadherin switching. J Cell Sci 2008, 121:727-735.

4. Takeichi M: Self-organization of animal tissues: cadherin-mediated processes. Dev Cell 2011, 21:24-26.

5. Dejana E, Tournier-Lasserve E, Weinstein BM: The control of vascular integrity by endothelial cell junctions: molecular basis and pathological implications. Dev Cell 2009, 16:209-21.

6. Micalizzi DS, Farabaugh SM, Ford HL: Epithelial-mesenchymal transition in cancer: parallels between normal development and tumor progression. J Mammary Gland Biol Neoplasia 2010, 15:117-134.

7. Labelle M, Schnittler HJ, Aust DE, Friedrich K, Baretton G, Vestweber D, Breier G: Vascular endothelial cadherin promotes breast cancer progression via transforming growth factor beta signaling. Cancer Res 2008, 68:1388-1397.

8. Nieman MT, Prudoff RS, Johnson KR, Wheelock MJ: N-cadherin promotes motility in human breast cancer cells regardless of their E-cadherin expression. J Cell Biol 1999, 147:631-644.

9. Hazan RB, Phillips GR, Qiao RF, Norton L, Aaronson SA: Exogenous expression of $\mathrm{N}$-cadherin in breast cancer cells induces cell migration, invasion, and metastasis. J Cell Biol 2000, 148:779-790.

10. Islam S, Carey TE, Wolf GT, Wheelock MJ, Johnson KR: Expression of Ncadherin by human squamous carcinoma cells induces a scattered fibroblastic phenotype with disrupted cell-cell adhesion. J Cell Biol 1996, 135:1643-1654.

11. Hendrix MJ, Seftor EA, Meltzer PS, Gardner LM, Hess AR, Kirschmann DA, Schatteman GC, Seftor RE: Expression and functional significance of VEcadherin in aggressive human melanoma cells: role in vasculogenic mimicry. Proc Natl Acad Sci USA 2001, 98:8018-8023.

12. Hess AR, Seftor EA, Gruman LM, Kinch MS, Seftor RE, Hendrix MJ: VEcadherin regulates EphA2 in aggressive melanoma cells through a novel signaling pathway: implications for vasculogenic mimicry. Cancer Biol Ther 2006, 5:228-33.

13. van der Schaft DW, Hillen F, Pauwels P, Kirschmann DA, Castermans K, Egbrink MG, Tran MG, Sciot R, Hauben E, Hogendoorn PC, Delattre O, Maxwell PH, Hendrix MJ, Griffioen AW: Tumor cell plasticity in Ewing sarcoma, an alternative circulatory system stimulated by hypoxia. Cancer Res 2005, 65:11520-11528.

14. Hay ED: An overview of epithelio-mesenchymal transformation. Acta Anat (Basel) 1995, 154:8-20.
15. Klymkowsky MW: beta-catenin and its regulatory network. Hum Pathol 2005, 36:225-227.

16. Zeisberg M, Neilson EG: Biomarkers for epithelial-mesenchymal transitions. J Clin Invest 2009, 119:1429-1437.

17. Hugo $H$, Ackland ML, Blick T, Lawrence MG, Clements JA, Williams ED, Thompson EW: Epithelial-mesenchymal and mesenchymal-epithelial transitions in carcinoma progression. I Cell Physiol 2007, 213:374-383.

18. Iwatsuki M, Mimori K, Yokobori T, Ishi H, Beppu T, Nakamori S, Baba H, Mori M: Epithelial-mesenchymal transition in cancer development and its clinical significance. Cancer Sci 2010, 101:293-299.

19. Thiery JP, Acloque H, Huang RY, Nieto MA: Epithelial-mesenchymal transitions in development and disease. Cell 2009, 139:871-890.

20. Huber MA, Kraut N, Beug H: Molecular requirements for epithelialmesenchymal transition during tumor progression. Curr Opin Cell Biol 2005, 17:548-558.

21. Brabletz T, Jung A, Reu S, Porzner M, Hlubek F, Kunz-Schughart LA, Knuechel R, Kirchner T: Variable beta-catenin expression in colorectal cancers indicates tumor progression driven by the tumor environment. Proc Natl Acad Sci USA 2001, 98:10356-10361.

22. Chaffer CL, Brennan JP, Slavin JL, Blick T, Thompson EW, Williams ED: Mesenchymal-to-epithelial transition facilitates bladder cancer metastasis: role of fibroblast growth factor receptor-2. Cancer Res 2006, 66:11271-11278.

23. Hudson LG, Zeineldin R, Stack MS: Phenotypic plasticity of neoplastic ovarian epithelium: unique cadherin profiles in tumor progression. Clin Exp Metastasis 2008, 25:643-655.

24. Chao YL, Shepard CR, Wells A: Breast carcinoma cells re-express Ecadherin during mesenchymal to epithelial reverting transition. Mol Cancer 2010, 9:179.

25. Oft M, Peli J, Rudaz C, Schwarz H, Beug H, Reichmann E: TGF-beta1 and Ha-Ras collaborate in modulating the phenotypic plasticity and invasiveness of epithelial tumor cells. Genes Dev 1996, 10:2462-2477.

26. Breier G, Blum S, Peli J, Groot M, Wild C, Risau W, Reichmann E: Transforming growth factor-beta and Ras regulate the VEGF/VEGF-receptor system during tumor angiogenesis. Int I Cancer 2002, 97:142-148.

27. Kuzmanov A, Wielockx B, Rezaei M, Kettelhake A, Breier G: Overexpression of factor inhibiting HIF-1 enhances tumor growth through improved blood vessel maturation. Int J Cancer 2012, 131:E603-613.

28. Jaggi M, Wheelock MJ, Johnson KR: Differential displacement of classical cadherins by VE-cadherin. Cell Commun Adhes 2002, 9:103-115.

29. Navarro P, Ruco L, Dejana E: Differential localization of VE- and N-cadherins in human endothelial cells: VE-cadherin competes with $\mathrm{N}$-cadherin for junctional localization. J Cell Biol 1998, 140:1475-1484.

30. Lee JM, Dedhar S, Kalluri R, Thompson EW: The epithelial-mesenchymal transition: new insights in signaling, development, and disease. $J$ Cell Biol 2006, 172:973-981.

31. Li H, Pamukcu R, Thompson WJ: beta-Catenin signaling: therapeutic strategies in oncology. Cancer Biol Ther 2002, 1:621-625.

32. Lustig B, Behrens J: The Wnt signaling pathway and its role in tumor development. J Cancer Res Clin Oncol 2003, 129:199-221.

33. Ishida K, Ito S, Wada N, Deguchi H, Hata T, Hosoda M, Nohno T: Nuclear localization of beta-catenin involved in precancerous change in oral leukoplakia. Mol Cancer 2007, 6:62.

34. Orsulic S, Huber O, Aberle H, Arnold S, Kemler R: E-cadherin binding prevents beta-catenin nuclear localization and beta-catenin/LEF-1-mediated transactivation. J Cell Sci 1999, 112:1237-1245.

35. Kawashima M, Kawakita T, Higa K, Satake Y, Omoto M, Tsubota K, Shimmura S, Shimazaki J: Subepithelial corneal fibrosis partially due to epithelial-mesenchymal transition of ocular surface epithelium. Mol Vis 16:2727-2732.

36. Gilles C, Polette M, Mestdagt M, Nawrocki-Raby B, Ruggeri P, Birembaut $P$, Foidart JM: Transactivation of vimentin by beta-catenin in human breast cancer cells. Cancer Res 2003, 63:2658-2664.

37. Bindels $S$, Mestdagt $M$, Vandewalle $C$, Jacobs $N$, Volders $L$, Noel $A$, van Roy F, Berx G, Foidart JM, Gilles C: Regulation of vimentin by SIP1 in human epithelial breast tumor cells. Oncogene 2006, 25:4975-4985.

38. Raymond WA, Leong AS: Vimentin-a new prognostic parameter in breast carcinoma? J Pathol 1989, 158:107-114.

39. Zhang X, Fournier MV, Ware JL, Bissell MJ, Yacoub A, Zehner ZE: Inhibition of vimentin or beta1 integrin reverts morphology of prostate tumor 
cells grown in laminin-rich extracellular matrix gels and reduces tumor growth in vivo. Mol Cancer Ther 2009, 8:499-508.

40. Luo Y, Radice GL: N-cadherin acts upstream of VE-cadherin in controlling vascular morphogenesis. J Cell Biol 2005, 169:29-34.

41. Tiraby C, Hazen BC, Gantner ML, Kralli A: Estrogen-related receptor gamma promotes mesenchymal-to-epithelial transition and suppresses breast tumor growth. Cancer Res 2011, 71:2518-2528.

42. Hong KO, Kim JH, Hong JS, Yoon HJ, Lee Jl, Hong SP, Hong SD: Inhibition of Akt activity induces the mesenchymal-to-epithelial reverting transition with restoring $\mathrm{E}$-cadherin expression in $\mathrm{KB}$ and $\mathrm{KOSCC}-25 \mathrm{~B}$ oral squamous cell carcinoma cells. J Exp Clin Cancer Res 2009, 28:28.

43. Graff JR, Herman JG, Lapidus RG, Chopra H, Xu R, Jarrard DF, Isaacs WB, Pitha PM, Davidson NE, Baylin SB: E-cadherin expression is silenced by DNA hypermethylation in human breast and prostate carcinomas. Cancer Res 1995, 55:5195-5199.

44. Vuoriluoto K, Haugen H, Kiviluoto S, Mpindi JP, Nevo J, Gjerdrum C, Tiron C, Lorens JB, Ivaska J: Vimentin regulates EMT induction by Slug and oncogenic $\mathrm{H}$-Ras and migration by governing $\mathrm{Axl}$ expression in breast cancer. Oncogene 2010, 30:1436-1448.

45. Peinado H, Olmeda D, Cano A: Snail, Zeb and bHLH factors in tumour progression: an alliance against the epithelial phenotype? Nat Rev Cancer 2007, 7:415-428

46. Berx G, Van Roy F: The E-cadherin/catenin complex: an important gatekeeper in breast cancer tumorigenesis and malignant progression. Breast Cancer Res 2001, 3:289-293.

47. Lombaerts M, van Wezel T, Philippo K, Dierssen JW, Zimmerman RM, Oosting J, van Eijk R, Eilers PH, van de Water B, Cornelisse CJ, CletonJansen AM: E-cadherin transcriptional downregulation by promoter methylation but not mutation is related to epithelial-to-mesenchymal transition in breast cancer cell lines. $\mathrm{Br} J$ Cancer 2006, 94:661-671.

48. Derksen PW, Liu X, Saridin F, van der Gulden H, Zevenhoven J, Evers B, van Beijnum JR, Griffioen AW, Vink J, Krimpenfort P, Peterse JL, Cardiff RD, Berns A, Jonkers J: Somatic inactivation of E-cadherin and p53 in mice leads to metastatic lobular mammary carcinoma through induction of anoikis resistance and angiogenesis. Cancer Cell 2006, 10:437-449.

doi:10.1186/bcr3367

Cite this article as: Rezaei et al:: Interplay between neural-cadherin and vascular endothelial-cadherin in breast cancer progression. Breast Cancer Research 2012 14:R154

\section{Submit your next manuscript to BioMed Central and take full advantage of:}

- Convenient online submission

- Thorough peer review

- No space constraints or color figure charges

- Immediate publication on acceptance

- Inclusion in PubMed, CAS, Scopus and Google Scholar

- Research which is freely available for redistribution

Submit your manuscript at www.biomedcentral.com/submit 